\title{
HEAVY DRINKING AND INTERPERSONAL VIOLENCE AT AND AROUND DIFFERENT ALCOHOL OUTLETS IN THE NORTH WEST PROVINCE, SOUTH AFRICA
}

\section{Nomonde Phetlho-Thekisho, Elizabeth Hermina Ryke, Herman Strydom}

\section{INTRODUCTION}

South Africa has one of the highest per capita alcohol consumption levels in the world, with social norms dictating that when people drink, then consumption is heavy. On the other hand, South Africa also faces a globally unprecedented problem of violence directed particularly against women - a situation which undermines the national development of the country, with possibilities even of hindering the achievement of the Millennium Development Goals (Jewkes, Abrahams, Mathews, Seedat, Van Niekerk, Suffla \& Ratele, 2009:1-2). There is substantial evidence from various researchers attesting to the relation between alcohol outlets and violence. However, the specific risk factors involved based on the geography of the outlets together with the dynamic nature and distribution of violence remain obscure. The objective of this study is to address this obscurity by investigating the risk factors in heavy drinking and interpersonal violence at and around different alcohol outlets in demarcated areas of the North West province of South Africa.

Interpersonal violence occurs mostly in and around the locations of alcohol outlets. Such places tend to attract clientele more likely to engage in violent acts (Gruenewald, Freisthler, Remer, Scala \& Treno, 2006:667). Research has also indicated that victims of these alcohol-related crimes are often under the influence of alcohol and that people who drink frequently are more at risk of being victimised (Felson \& Burchfield, 2004:837). The alcohol outlets referred to in this study are categorised as: shebeens, which are private homes (mostly unlicensed), where alcoholic beverages are sold and served on or off premise, while taverns and night clubs are on-site places of consumption where alcoholic beverages are sold and they are predominantly licensed (Morojele, Kachieng'a, Mokoko, Nkoko, Parry, Nkowane, Moshia \& Saxena, 2006:220).

Historically many people without formal employment, particularly women from poor black communities, are said to have earned a living by selling liquor illegally from shebeens in South Africa. The consequences include countless raids, harassment, arrests, prosecutions and imprisonment. Also, the drinking of liquor led to social breakdown, family violence and alcohol-related diseases in most poor black communities (Parry \& Bennett, 1998:85). A large illegal liquor trade emerged in the black townships (Africa, 2005:3). It is estimated that there are more than 200000 illegal alcohol outlets across South Africa (SABC News, 2006:1).

Heavy drinking as viewed in this study encompasses a drinking occasion leading to intoxication with acute health and social impacts. The tendency is for such drinkers to frequently consume large quantities in a short period without eating properly, mostly over weekends, and to drink in order to get drunk (Obot, 2006:21; WHO, 2004:5). The 
terms "heavy drinking" and "binge drinking" are used interchangeably in this study. Interpersonal violence is violence inflicted by an individual or small group of individuals on another/others and includes mainly physical and sexual assault (WHO, 2005:1).

\section{RESEARCH METHODOLOGY}

\section{Research design}

Qualitative research with snapshots as a form of research design was used. This research design was used to identify themes and commonalities from what was observed in and around the identified alcohol outlets, including the collection of different manifestation of expertise and other types of information in the form of interviews and from documents (Flick, 2006:142).

\section{Data-collection method}

As a qualitative data-gathering technique, observation was used to gain a deeper insight into and understanding of the phenomenon of heavy drinking and associated interpersonal violence at and around different alcohol outlets. Observations were carried out unobtrusively at a total of 24 alcohol outlets in the Bophirima and the southern regions of the North West province of South Africa. The observation sites were purposefully sampled to reflect the rural-urban and informal settlement dichotomy from the demarcated sites. Table 1 displays the profile of alcohol outlets visited.

The venues for an urban area to be observed were a shebeen, a tavern and a night club. In a rural area they were a shebeen and a tavern, while for an informal settlement area it was mainly a shebeen.

For optimal observation, the researcher assumed the role of observer as participant. As a researcher, one settles into a situation and focuses mainly on the role of observer in the situation. One also looks for patterns of behaviour in a community in order to investigate the assumptions, values and beliefs of the observed and to even make sense of the social dynamics. The researcher does, however, not influence the dynamics of a setting (Nieuwenhuis, 2007:5).

Predetermined categories of behaviour and situations one would like to observe are identified and developed into a guideline/schedule (Polit \& Beck, 2008:402) (see Table 2). Data were captured two-dimensionally: this consisted of one's description of what is observed and one's reflection on what is happening (Nieuwenhuis, 2007:85-86). Key informants such as community leaders facilitated entrance into the social setting and identification of the public drinking places. Each drinking place was visited twice and was observed over a four-hour session per visit. Observations took place midweek and over weekends, during night times and during the day. Both the exterior and interior environment of the public drinking places were observed. 
TABLE 1

PROFILE OF THE ALCOHOL OUTLETS VISITED

\begin{tabular}{|c|c|c|c|}
\hline REGION & $\begin{array}{l}\text { NATURE } \\
\text { OF AREA }\end{array}$ & $\begin{array}{c}\text { TYPE OF ALCOHOL } \\
\text { OUTLET }\end{array}$ & $\begin{array}{c}\text { ESTIMATE NUMBER } \\
\text { OF PATRONS } \\
\text { OBSERVED } \\
\end{array}$ \\
\hline \multirow[t]{5}{*}{ SOUTHERN } & $\begin{array}{l}\text { URBAN } \\
\text { Established } \\
\text { Urban }\end{array}$ & 3 Night clubs & $\begin{array}{l}-120 \\
-120 \\
-110\end{array}$ \\
\hline & \multirow[t]{2}{*}{ Urban } & 2 Night clubs & $\begin{array}{l}-140 \\
-100 \\
\end{array}$ \\
\hline & & 4 Taverns & $\begin{array}{l}-80 \\
-70 \\
-\quad 70 \\
-\quad 79\end{array}$ \\
\hline & & 2 Shebeens & $\begin{array}{l}-45 \\
-\quad 50 \\
\end{array}$ \\
\hline & $\begin{array}{l}\text { Informal } \\
\text { settlement }\end{array}$ & 2 Shebeens & $\begin{array}{l}-48 \\
-\quad 49\end{array}$ \\
\hline \multirow[t]{5}{*}{ BOPHIRIMA } & $\begin{array}{l}\text { RURAL } \\
\text { Urban rural }\end{array}$ & 3 Taverns & $\begin{array}{l}-55 \\
-56 \\
-50 \\
\end{array}$ \\
\hline & & \multirow[t]{2}{*}{4 Shebeens } & -34 \\
\hline & & & $\begin{array}{l}-\quad 32 \\
-\quad 30 \\
-\quad 30\end{array}$ \\
\hline & Very rural & \multirow[t]{2}{*}{4 Shebeens } & -30 \\
\hline & & & $\begin{array}{l}-\quad 30 \\
-\quad 34 \\
-\quad 38 \\
\end{array}$ \\
\hline TOTAL & 3 & 24 & 1500 \\
\hline
\end{tabular}

\section{Ethical consideration}

Ethical approval for this study was obtained from the North West University (No. NWU-00047-07-S7). To gain entry to the demarcated areas, permission was granted by the Executive Mayor and the Traditional Councils. Patrons and managers/owners of alcohol outlets selected for member checking completed consent forms.

\section{Analysis}

Analysis of data was done after the entire observation process was completed. Detailed field notes were read over and over again once they were documented. From these field notes, categories were produced and were validated informally through member checking - comprising four patrons and four owners of taverns, who were purposefully selected from alcohol outlets. This entails verifying the understanding of what was observed regarding those observed (Nieuwenhuis, 2007:86). Finally, the seven categories/themes emerged and are discussed under findings. 
TABLE 2

GUIDELINE/SCHEDULE FOR UNSTRUCTURED OBSERVATIONS

\section{EXTERIOR ENVIRONMENT}

Location of alcohol drinking outlet;

Influence of the alcohol drinking outlet on the neighbourhood;

Observable facilities of the alcohol drinking outlet (such as parking);

Number of alcohol drinking outlets per street/neighbourhood.

2. INTERIOR ENVIRONMENT

\section{Basic Information:}

Type of alcohol drinking outlet; Time of visit; Day of visit; Duration of visit.

\section{Security:}

Availability; Attitude displayed; Effectiveness; Existence of safety rules; How violent behaviour is prevented and managed.

\section{Patrons:}

Gender; Age group; Alcohol consumption patterns; Type of alcohol served.

\section{Characteristics of premises:}

Space; Seating availability and arrangements; Ventilation; Maintenance of place and equipment; Days and times of discounted alcoholic drinks; lighting; Colour of wall painting; Type of music and pitch; Permissiveness of deviant behaviour such as serving of alcohol to the under-aged, serving of alcohol to those already intoxicated, allowing swearing and overt sexual activity; Times of operation; Ownership of the alcohol drinking outlet.

\section{Limitations}

Bearing in mind the usefulness of observation as a data-gathering technique, namely enabling the researcher to gain a deeper insight into and understanding of the phenomenon being observed, it is necessary, however, to note the limitations of the study. The nature of the method of data collection used was not amenable to address a wide range of issues, such as reasons why people displayed certain characteristics or mannerisms. Interviewing people about these issues remains the only means of finding out more about them, but this was not catered for in the observation method used.

It is acknowledged explicitly that the nature of the study made it impossible to implement the usual courtesies commonly extended to participants. For instance, unobtrusive observations were carried out in a public environment which is uncontrollable (in terms of not knowing which patrons will come to the alcohol outlet, and how long they will stay), with managers of alcohol outlets being highly suspicious of anybody who does not come in as a patron.

\section{FINDINGS}

\section{Proximity and density of alcohol outlets}

Licensed alcohol outlets such as taverns and night clubs are commonly situated in the central business district (CBD) near banks, ATM facilities, post offices and retail shops. Shebeens, on the other hand, are situated in residential areas, mostly in close proximity to schools, places of worship and other shebeens. A marked feature of most drinking 
places during the observation period was the playing of loud music during the trading hours of the drinking place, which is virtually the entire day and night. This often coincided with the trading hours of nearby businesses, worship times for others and resting or sleeping times for most families. Normal functioning and production can therefore be impeded by the noise and the social interactions of people attracted by the music and drinking place.

After a busy weekend at most drinking places, the pavement carries traces of blood, broken bottles and broken windows, used condoms, heaps of empty tins and cigarettes. The heavy smell of urine also poses a health challenge for nearby residences and businesses. "Who is responsible for the damage and mess and therefore accountable for related fixing and cleaning"? These are questions that go unanswered and have often resulted in conflict between alcohol outlets and nearby residents and businesses. In residential areas heaps of such refuse become scattered all over the place, including in people's yards. Children would be seen running around with used condoms, making the neighbourhood unbearable and unhealthy.

It was a common sight to see employees supposedly on duty visiting the alcohol outlet at times such as at $10 \mathrm{~h} 00$ in the morning. In alcohol-drinking circles Monday mornings are known to be "blue", presumably because many people are suffering from a hangover, especially when the weekend was characterised by high alcohol intake. Ten o'clock, a tea break for employees, sees the affected ones quickly rushing to a drinking place for a "fix". Already known and expected, they are served their "shots" in cold drink tins which they would carry back to the office unsuspectingly. Some would even not go back to work after their lunch break.

In terms of density of drinking places, it was also common for five shebeens to be located and operational in one street. Propelled by fierce competition and conflict, owners of the drinking places would often use patrons to provoke violence at their competitors' drinking places to discredit them. It was evident that facilities such as parking spaces and ablution facilities were lacking at most drinking places, especially shebeens. In the CBD patrons of drinking places use reserved parking meant for customers of nearby businesses. Some of the patrons would even demand that the security car attendants on duty look after their cars, often without payment. In residential areas patrons would park their cars right in front of other people's yards. During peak periods, such as over weekends, the patrons would even park in driveways of residences without permission. In certain instances it was also common to see men who were visiting nearby shebeens urinating on the neighbour's pavement, or in the private garden. Occasionally it would be under the trees or even next to the wall. This would take place in full view of the residents and even children.

\section{Social and physical factors of alcohol outlets}

Alcohol outlets in the informal settlement area mirror most of the characteristics and features of the area in which it is located. These include:

- Normlessness - there is a disregard for rules, if any, and authority. Most of the patrons usually come to the drinking places armed with weapons such as knives, 
sharp instruments and firearms. At the slightest provocations these are readily pulled out;

- Inappropriate setting - alcohol outlets in informal settlements operate on nondesignated land for human occupation - an area not easily reached by the police, the ambulance or any emergency service. The close proximity of patrons within the drinking place also accounts for various activities such as sexually provocative dancing, sexual acts and physical fights. These are openly witnessed by people of the neighbourhood, including children;

- Disorderliness - there is permissiveness of deviant behaviour such as selling of alcohol to those already intoxicated, to pregnant women, to nursing women, some even with babies on their back, to those apparently under the age of 18 years (the legal age for drinking alcohol in South Africa) and to school children in uniform. There is also swearing as well as overt sexual activities such as patrons touching others inappropriately.

In most of the licensed drinking places, disorderliness was also evident from poorly maintained facilities such as toilets not working well and patrons having to share one toilet, which poses a physical danger and a health hazard. The drinking places are generally poorly ventilated, making the atmosphere stuffy, hot and moist. Walls are dark and lights are dim. The type of music is sexually provocative and tends to create a sexually permissive atmosphere. Since most drinking places operate on "the more the merrier" principle, existing capacity is often exceeded. The number of people in the venue leaves no room for free movement lest one spills another person's drink, a real probability especially after consuming some alcohol. This does contribute to the outbreaks violence, especially when the spilled drink cannot be replaced.

\section{Off-peak and peak periods}

Alcohol drinking places do experience cyclical off-peak and peak periods. These periods differ in licensed outlets from those that are not licensed.

During off-peak periods in most licensed alcohol outlets, promotional and discounted events are held. The apparent aim of such events ranges from showcasing a new product and introducing patrons to it, getting rid of old alcohol stock that is unpopular with patrons, and boosting trade, especially in the middle of the week and the middle of the month. The two types of events that were popular during the observation period were Ladies' Night and Happy Hours.

The Ladies' Night event at most of the alcohol outlets took place every Wednesday from about $21 \mathrm{~h} 00-23 \mathrm{~h} 00$. Times are not fixed at all drinking places. The local colloquial term for Wednesdays, "Pekenene Weekend" (mini-weekend), describes the night. During such an event, ladies or female patrons either qualify for free admission at a night club where an entrance fee is normally charged, or for entering a draw for which the prize might be a bottle of alcohol. The most common marketing strategy witnessed was one indicating that "the first hundred ladies entering the night club will receive free drinks and snacks". The alcoholic beverage on offer would be wine. The rationale for a 
Ladies' Night is mostly based on the idea that the presence of female patrons will attract men patrons, and the drinking place thus in turn realising higher profits.

Women who buy into this promotional event often come beautifully dressed. In other words, not only is an alcohol product showcased, but so are the women. Men who are thereby attracted would then further entertain their choice of women selected from the beautifully clad ones with alcohol, often of a different brand from the one used for the promotion. The situation often results in intoxication. Most men, after parting with their cash, would demand some form of gratification as reimbursement. The demand is mostly for this to be in kind (a form of sexual favours). This behaviour stems from the stereotyping of women.

During the Happy Hours patrons might qualify for two drinks for the price of one for a limited period. The promotion is often linked to a popular sports event such as a football and/or a rugby match. Patrons would qualify for half price on a beer for maybe 15 minutes after the home team scored. One minute after the provided time, the special offer would expire. Patrons influenced by such offers would often binge, by drinking quickly, drinking large amounts, and ending up mixing products and/or brands in the atmosphere of excitement.

The peak periods in most of the unlicensed drinking places are during weekends, especially at the end of the month. What was conspicuous in most rural and informal settlements was the coinciding of peak periods with the pay-out days for social assistance - the child support grant (CSG) to be specific. The primary care givers, mostly single women in their middle twenties, are known to be misdirecting money meant for the protection and maintenance of children to maintain an alcohol habit - a form of child neglect and abuse. Since the CSG does provide regular contributions to the care givers, this seems to serve as a kind of security, enabling them to buy alcohol on credit.

\section{Security}

At most of the drinking places security in the form of a person or people guarding the door or gate is virtually non-existent. Instances where alarm devices are used the notice clearly states that the premises are protected against burglary, but that no protection is afforded for the people.

At most of the night clubs and taverns where live bands played, men acted as security guards during peak periods. These men are commonly known as "bouncers". Since physical strength is one of the prerequisites, many licensed outlets hire former soldiers, policemen or body builders to execute this task. At other drinking places security services are executed by pensioners in their sixties or young men in their late twenties, who never underwent any form of specialised security training. The bouncers mostly serve on a part-time basis, and are expected to carry out the manager's instructions to the letter, often without consideration of the basic human rights of people. Their task is to protect the business, including management, and equipment. 
Irrespective of who might have started the fight, bouncers can eject all whom they view as problematic and as misbehaving. Their apparently confrontational nature often aggravates the very violence they want to quell. Some drinking places operate on the premise that when people fight and are uncontrollable after drinking a lot, they should be advised to leave or, if they refuse, rather to be ejected. This is to protect the name of the drinking place, which is not to be put in disrepute on accounts of reported violent crime or even deaths. Some patrons are aware of these practices and procedures, and so would take advantage of intoxicated women, who would ultimately end up being prey and victimised.

Security staff is also occasionally expected to carry out body searches to prevent people from entering the premises with weapons. Powerful people with money often buy their way through.

\section{Type of alcohol consumed}

Though recorded alcohol such as beer is popular at most licensed drinking places, unrecorded alcohol such as sorghum beer, including concoctions made from harmful ingredients, were more affordable at most unlicensed drinking places. A jar (equivalent to $750 \mathrm{ml}$ ) would cost about $\mathrm{R} 5.00$, with the ingredients made up of things such as mentholated spirits, car battery acid and steel wool. These concoctions are more affordable but pose a health hazard. In rural and informal settlements both men and women are users.

Also evident in these areas was the presence of drinking networks. These are groups of friends supporting each other's drinking habit. They buy drinks for one another and in most instances will even drink from the same container in a round robin way.

\section{Ownership of the alcohol business}

What was evident from the observations was how gendered the ownership of the type of drinking places is. For instance, most of the licensed venues such as taverns and night clubs are owned and controlled by men, whereas shebeens, which are mostly unlicensed, small and therefore informal, appears to be the territory mainly of women. Most women either run these single-handedly or with the help of other members of their family, the girl child in particular. Some of the factors contributing to making children vulnerable to violence and heavy drinking are trading hours that are not fixed. During peak days, such as over weekends and at the end of the month, it is very common for the business to operate from "dawn to dawn", and to share all facilities in the house with strangers. There are instances where sleeping accommodation is even made available to some patrons. The sobriety of the shebeen queen, who happens to be the mother, is also not guaranteed, thus creating a situation where children lack parental protection. Serving of alcohol by children can also lead to premature intake and can also be viewed as a form of child labour - a criminal act in South Africa.

\section{Seating arrangements and drinking patterns}

In a drinking place people are normally not ushered to specific seats. There were two distinct areas in most taverns and night clubs, namely the bar area and the hallway with a 
dancing space. The bar area was mostly occupied by older men in their forties with buying power. The hallway was mostly occupied by both men and women. In this category young men in their late twenties dominated the sales. In a shebeen the seating arrangement is not gendered. People with buying power are in general conspicuous, known, and are mostly in their forties.

Most men with buying power demand attention and are afforded ownership and control of processes such as the music to be played, the patron or patrons to be removed, and the woman or women they want to end the night with. The drinking places benefit from this buying power through the use of "up-selling". For instance, if the customer orders a tot of spirit, he is normally convinced to buy the whole bottle on the basis that doing so represents a better value that coincides with their physical status. In order to live up to the image of masculinity and power, they normally give in to up-selling and end up drinking heavily.

\section{DISCUSSION}

It is worth noting from this study that assaultive alcohol-related violence does cluster near agglomerations of alcohol outlets. Violent incidences would emanate from situations where intoxicated people would urinate in public or on private property, vandalise facilities, be violent towards others and be guilty of noise violations, with an extremely high propensity to economic and social disintegration in such communities.

The results of this research are congruent with local and international research findings. For example, in New Zealand researchers Day, Breetzke, Kingham and Campbell (2012:51) found that an increase in alcohol outlet density leads to an increase in the area-level crime, which in turn increases both alcohol outlet density with manifestations in social deprivation. On the local front Mdhladhla (2012:2) found that communities in South Africa are indeed complaining that most taverns are situated around schools, churches and main roads. Regarding the schools, the alcohol outlets impact greatly on the discipline in schools and encourage learners to bunk classes and to consume large amounts of alcohol. Those positioned around places of worship normally show very little respect for the beliefs of the worshippers by playing loud music during times of service. Such behaviour often leads to animosity and eventually to violence. Those positioned on the main road have led to countless accidents caused by people who "drink and drive" and those who "drink and walk", a contravention of the Liquor Act, 2003 (Act No. 59 of 2003).

In South Africa shebeen permits applications have hitherto been subjected to minimal conditions and requirements based on their location of operation. As a result the monitoring of such operations and enforcing compliance with legislation have been compromised. This is because liquor-selling venues in residential areas are operating on premises that are not zoned for business use, thus there is an absence of appropriate facilities, which in itself is a violation of municipal by-laws (Gauteng Draft Liquor Policy, 2011:1). 
Another notable contribution of this study is that there are physical and social factors associated with higher levels of heavy drinking and violence. Indicators are poorly maintained facilities; permissiveness of deviant behaviour; overcrowding; and serving of alcohol to those already intoxicated. Similar studies yielded the following results: Quigley and Leonard (2004/2005:193) found that participants in their study were more likely to report that violent bars were smokier, hotter, dirtier, darker, more crowded and more likely to have competitive games, whereas Graham, Bernads, Osgood, Homel and Purcell (2005:764) found violent bars to be more run down, to serve patrons already intoxicated and to have an "anything goes" atmosphere. Disorderliness does rub off on patrons.

The different marketing styles used to contribute to the misuse of alcohol and violence emerged from the findings that marketing places a heavy emphasis on profits to the detriment of people (patrons), using women as pawns in an alcohol-for-profit game, and a marketing style that is aggressive. The MCM Research (2004:12) findings concur with the present results, namely that some of the promotional events used are "aggressive", irresponsible and inappropriate marketing, such as reducing the price to beat the price of the pub next door. Jernigan and Obot (2006) found that, in Nigeria, the marketers tout the health benefits of beer. For example, in their advertisements readers are informed about how rich beer is in antioxidants, which help in warding off cancer. Hence it is a "health tonic" when consumed in moderation, they say.

The sexual stereotyping of women was a norm with most men at different drinking places, based on the belief that a woman who accepts drinks from a man is willing to sleep with that man as a form of repayment, contributing to sexual violence. Patriarchal notions of masculinity related to men's control and ownership of women and space prevailed. These findings are consistent with the stereotypical view that, when a woman accepts a beer from a man, she is obliged to exchange that for sex (because she has "drunk his money"). Also those women who dress in a so-called sexually provocative manner or get drunk are more likely to be perceived as "loose" or sexually "easy" by men in general. Importantly, the shebeen environment appears to support an acceptance of the view that women who are raped or physically attacked do not receive aid from others. Rather, it is believed that women who accept drinks from men owe these men sexual favours. A number of phrases are used to describe this widespread belief, including "she drank his money" "she baked the cake" and "if you feed a horse, you ride it" (Parks \& Scheidt, 2004; Wojcicki, 2002; Wojcicki, 2000).

The present study found the peak periods in different drinking places to be over weekends, particularly at the end of the month. It was evident in most rural communities and in the informal settlements that the peak periods coincided with the pay-out days for social assistance. Money meant for the maintenance of children and families maintains a habit of alcohol consumption. Contrary to the present findings, the study by Leatt, Meintjies and Berry (2005) revealed that there is substantial evidence that social grants, including the child support grant (CSG), are being spent on food, education and basic goods and services. 
Generally there is no security for patrons at different drinking places, especially in unlicensed establishments. In licensed drinking places where there is security in the form of people guarding the gate or door, this ranges from people without specialised security training to bouncers who are confrontational in their approach. This approach causes more violence (harm) than dealing with it (good).

Beer and traditional homemade brew (concoctions) contributed significantly to the overall high alcohol consumption at most alcohol outlets based on their affordability and availability. Drinking networks support and maintain excessive drinking habits for men. The traditional homemade brew is usually made from harmful ingredients, with very serious health repercussions. Thabethe (2011:1) alludes to the fact that the abuse of alcohol in South Africa costs the economy about R9 billion a year, amounting to $1 \%$ of the country's gross domestic product. The irony of this is that alcohol is a legal drug locally and worldwide, and that the alcohol industry is also playing a role in the economy of South Africa as a developing society in especially three ways: firstly, alcohol production and distribution contributes to the gross national product; secondly, alcohol sales contribute to state revenue through excise duties and other taxes; and thirdly, the liquor industry is a huge employer in South Africa (WHO, 2006:9). This poses as an obstacle to change.

On the whole, shebeen queens dominate the shebeen businesses, which are informal, small and mostly illegal, while taverns and night clubs are mostly owned by men - a clear gender division of resources and opportunities. These apparently female-headed households tend to rope in members of their family, the girl children in particular, in the running of the shebeen business - some form of child labour, thus exposing them to abuse and violence, aggravated because the sobriety of the mother is not guaranteed. While this is a problem in its own right, it can also give rise to intergenerational cycling of violence. Most girl children exposed to physical, sexual and emotional abuse as children tend to be at increased risk of re-victimisation as adults (Jewkes et al., 2009:1).

In the South African situation the illegality of child labour is clearly indicated in the Basic Conditions of Employment Act (Act 11 of 2002) and the Child Care Act (Act 74 of 1983 as amended). These Acts clearly state, among other things, that: no person may employ a child in places that risk the child's wellbeing, his or her educational, physical or mental as well as his or her spiritual, moral or social development. Penalties for the contravention of these provisions may range from a fine to a three-year sentence (Peacock \& Booyens, 2007:182). Enforcing compliance raises significant challenges.

\section{CONCLUSIONS AND RECOMMENDATIONS}

Overall, the study contributes to a better understanding of risk factors associated with heavy drinking and associated violence in the social context of both licensed and unlicensed alcohol outlets. Since the dawn of the democratic dispensation in South Africa in 1994 various pieces of legislation, policies and regulations have been enacted to regulate public alcohol drinking places in terms of alcohol abuse and violence. Amidst these written changes, the view is that there are an incongruence between 
64

policies and practices. Stringent measures are to be enacted for compliance with policies, based on the following recommendations in terms of practice and policy:

- Improved management of public liquor outlets: Tailor-made training courses can be offered to emerging entrepreneurs entering the liquor trade. The emphasis can be placed particularly on: conflict management; management of equipment and facilities; responsible marketing strategies that are non-aggressive; effective security systems; and prohibition of child labour. Training offered is to be SAQA compliant and can also be offered in any of the eleven indigenous South African languages;

- Decentralisation of services: By operating where licences are needed, licence regulators can obtain first-hand information regarding the capacity that the area in question can accommodate, including whether the premises meet the legal requirements;

- Assessments at multiple levels including the micro level: A systematic monitoring and evaluation mechanism that is culturally sensitive and provincially specific can be put in place at local level to ensure compliance of liquor traders with the alcohol policy, with social workers leading the process of change.

In conclusion, there is a need for skilling people in order to widen their choice of different business ventures.

\section{REFERENCES}

AFRICA, D. 2005. Address by North West MEC for Finance and Economic Development, during Local Enterprise Task System (LETS): Small Business Seminar, South African Government Information. [Online] Available: http://www.info.gov.za/ speeches/2005 05063008151003.htm. [Accessed: 11/01/2008].

BASIC CONDITIONS OF EMPLOYMENT ACT. 2002. Republic of South Africa. Act No. 11 of 2002. Pretoria: Government Printer.

CHILD CARE ACT. 1983. Republic of South Africa. Act No. 74 of 1983 as amended. Pretoria: Government Printer.

DAY, P., BREETZKE, G., KINGHAM, S. \& CAMPBELL, M. 2012. Close proximity to alcohol outlets is associated with increased serious violent crime in New Zealand. Australian and New Zealand Journal of Public Health, 36(1):48-54.

FELSON, R.B. \& BURCHFIELD, K.B. 2004. Alcohol and the risk of physical and sexual assault victimization. Criminology, 42(4):837-859.

FLICK, U. 2006. An introduction to qualitative research. London: Sage Publications.

GAUTENG PROVINCIAL DRAFT LIQUOR POLICY. 2011. Responsible distribution promotion sale and consumption of liquor. Department of Economic Development: Unpublished.

GRAHAM, K., BERNADS, S., OSGOOD, D.W., HOMEL, R. \& PURCELL, J. 2005. Guardians and handlers: the role of bar staff in preventing and managing aggression. Society for the Study of Addiction, (100):755-766. 
GRUENEWALD, P., FREISTHLER, B., REMER, L., LA SCALA, E.A. \& TRENO, A. 2006. Ecological models of alcohol outlets and violent assaults: crime potentials and geospatial analysis. Addiction, (101):666-677.

JERNIGAN, D.H. \& OBOT, I.S. 2006. Thirsting for the African Market. African Journal of Drug \& Alcohol Studies, (5):57-70.

JEWKES, R., ABRAHAMS, N., MATHEWS, S., SEEDAT, M., VAN NIEKERK, A., SUFFLA, S. \& RATELE, K. 2009. Preventing rape and violence in South Africa: call for leadership in a new age for action. MRC Policy Brief. Pretoria: Medical Research Council.

LEATT, A., MEINTJIES, H. \& BERRY, L. 2005. Children's access to social assistance. In: JACOBS, M., SHUNG-KING, M. \& SMITH, C. (ed) South African child gauge. University of Pretoria: Children's Institute.

LIQUOR ACT. 2003. Republic of South Africa. Act No. 59 of 2003. Pretoria: South African Government Printer.

MCM RESEARCH. 2004. Report of research and consultation conducted by MCM Research Ltd for Wine Intelligence. St Clements: Oxford.

MDHLADHLA, Z. 2012. The effects of the location of outlets, density and trading hours on communities. An address at the DTI Liquor Regulation Convention on: towards a balanced and effective liquor regulation framework. Held at the Gallagher Estate, Johannesburg: Unpublished.

MOROJELE, N.K., KACHIENG'A, M.A., MOKOKO, E., NKOKO, M.A., PARRY, C.D.H., NKOWANE, A.M., MOSHIA, K.M. \& SAXENA, S. 2006. Alcohol use and sexual behaviour among risky drinkers and bar and shebeen patrons in Gauteng Province, South Africa. Social Science \& Medicine, 62(1):217-227.

NIEUWENHUIS, J. 2007. Qualitative research designs and data gathering techniques. In: MAREE, K. (ed). First steps in research. Pretoria: Van Schaik Publishers.

OBOT, I.S. 2006. Alcohol use and related problems in Sub-Saharan Africa. African Journal of Drug and Alcohol Studies, 5(1):17-26.

PARKS, K.A. \& SCHEIDT, D.M. 2004. Male bar drinkers' perspective on female bar drinkers. Sex Roles, 42(11-12):927-941.

PARRY, C.D.H. \& BENNETT, A. 1998. Alcohol policy and public health in South Africa. United Kingdom, Oxford University Press.

PEACOCK, R. \& BOOYENS, K. 2007. Victimisation vulnerability of children. In: DAVIS, L. \& SNYMAN, R. (eds). Victimology in South Africa. Pretoria: Van Schaik Publishers.

POLIT, D.F. \& BECK, C.T. 2008. Foundation of nursing research and evidence based practice. Philadelphia: J.B. Lippincott.

QUIGLEY, B.M. \& LEORNARD, K.E. 2004/2005. Alcohol use and violence among young adults. Alcohol Research and Health, 28(4):191-194. 
66

SABC NEWS. 2006. Authorities to clamp down on illegal liquor trade. [Online] Available: $\quad$ http://www.Sabcnews.com/south-africa/crimeljustice/0,2172,128230,00. html. [Accessed: 28/5/2007].

THABETHE, E. 2011. Alcohol abuse costs R9bn a year. News 24. Unpublished.

WHO. 2004. Global Status Report on Alcohol. Geneva: World Health Organization.

WHO. 2005. Alcohol and Interpersonal Violence Policy Briefing. Geneva: World Health Organization.

WHO. 2006. Alcohol in developing Societies Summary. Geneva: World Health Organization.

WOJCICKI, J.M. 2000. An acceptance of violence: rape, shebeens and HIV. International Conference on AIDS - Abstract No. LBPeD 71222, July 9-14. [Online] Available: http://ww.gateway.hlm.nih.gov/meeingAbstracts/102242636html. [Accessed: 11/01/2008].

WOJCICKI, J.M. 2002. "She drank his money": survival sex and the problem of violence in taverns in Gauteng Province, South Africa. Medical Anthropology Quarterly, 16(3):267-293.

Dr Nomonde Phetlho-Thekisho, Department of Social Work, North-West University, Mafikeng Campus; Prof Elizabeth Hermina Ryke, Prof Herman Strydom, School of Psychosocial Behavioural Sciences (Social Work), North-West University, Potchefstroom, South Africa. 